\title{
Fatty acid synthase (FASN) regulates the mitochondrial priming of cancer cells
}

\author{
Barbara Schroeder ${ }^{1,2,12,15}$, Travis Vander Steen ${ }^{1,15}$, Ingrid Espinoza ${ }^{3,4,15}$, Chandra M. Kurapaty Venkatapoorna ${ }^{1,13}$, Zeng Hu ${ }^{1,14}$, \\ Fernando Martín Silva (iD ${ }^{5}$, Kevin Regan ${ }^{6}$, Elisabet Cuyàs (D) ${ }^{7,8}$, X. Wei Meng ${ }^{9}$, Sara Verdura ${ }^{7,8}$, Aina Arbusà, ${ }^{7,8}$, Paula A. Schneider ${ }^{9}$, \\ Karen S. Flatten ${ }^{9}$, George Kemble ${ }^{10}$, Joan Montero (iD) ${ }^{5}$, Scott H. Kaufmann (iD) ${ }^{2,9}$, Javier A. Menendez (iD ${ }^{6,7 凶}$ and Ruth Lupu (iD)
}

(c) The Author(s) 2021

Inhibitors of the lipogenic enzyme fatty acid synthase (FASN) have attracted much attention in the last decade as potential targeted cancer therapies. However, little is known about the molecular determinants of cancer cell sensitivity to FASN inhibitors (FASNis), which is a major roadblock to their therapeutic application. Here, we find that pharmacological starvation of endogenously produced FAs is a previously unrecognized metabolic stress that heightens mitochondrial apoptotic priming and favors cell death induction by $\mathrm{BH} 3$ mimetic inhibitors. Evaluation of the death decision circuits controlled by the $\mathrm{BCL}-2$ family of proteins revealed that FASN inhibition is accompanied by the upregulation of the pro-death BH3-only proteins BIM, PUMA, and NOXA. Cell death triggered by FASN inhibition, which causally involves a palmitate/NADPH-related redox imbalance, is markedly diminished by concurrent loss of BIM or PUMA, suggesting that FASN activity controls cancer cell survival by fine-tuning the BH3 only proteinsdependent mitochondrial threshold for apoptosis. FASN inhibition results in a heightened mitochondrial apoptosis priming, shifting cells toward a primed-for-death state "addicted" to the anti-apoptotic protein BCL-2. Accordingly, co-administration of a FASNi synergistically augments the apoptosis-inducing activity of the dual BCL- $\mathrm{X}_{\mathrm{L}} / \mathrm{BCL}-2$ inhibitor $\mathrm{ABT}-263$ (navitoclax) and the $\mathrm{BCL}-2$ specific BH3-mimetic ABT-199 (venetoclax). FASN inhibition, however, fails to sensitize breast cancer cells to $M C L-1-$ and $B C L-X_{L}-$ selective inhibitors such as $\mathrm{S} 63845$ and A1331852. A human breast cancer xenograft model evidenced that oral administration of the only clinically available FASNi drastically sensitizes FASN-addicted breast tumors to ineffective single-agents navitoclax and venetoclax in vivo. In summary, a novel FASN-driven facet of the mitochondrial priming mechanistically links the redox-buffering mechanism of FASN activity to the intrinsic apoptotic threshold in breast cancer cells. Combining next-generation FASNis with BCL2-specific BH3 mimetics that directly activate the apoptotic machinery might generate more potent and longer-lasting antitumor responses in a clinical setting.

Cell Death and Disease (2021)12:977; https://doi.org/10.1038/s41419-021-04262-x

\section{INTRODUCTION}

Elevated de novo fatty acid (FA) biogenesis driven by the activation of lipogenic enzymes is one of the most common metabolic traits that provide proliferative and survival advantages to tumors [1-7]. Fatty acid synthase (FASN) is a key enzyme in the endogenous lipogenesis pathway that primarily catalyzes the synthesis of the long-chain saturated FA palmitate from acetyl-CoA and malonylCoA, using NADPH as a reducing agent [8-11]. FASN activation is an early and near universal hallmark of most human carcinomas and their precursor lesions, and is enhanced in a stage-dependent manner that associates with worsened patient survival and therapeutic resistance. Interest in FASN-driven lipid signaling as a target for therapeutic intervention stemmed from findings more than a decade ago that tumor cells show reduced growth and viability upon targeted FASN suppression $[8,9,11-14]$. Since then, however, we have been unable to resolve the discrepancy between the basic science-discovery bench aspects of FASN blockade and the awaited bedside effects of FASN inhibitors (FASNis).

The demonstration of target engagement and early signs of clinical activity in cancer patients receiving next-generation

\footnotetext{
${ }^{1}$ Division of Experimental Pathology, Department of Laboratory Medicine and Pathology, Mayo Clinic, Rochester, MN 55905, USA. ${ }^{2}$ Mayo Clinic Cancer Center, Rochester, MN 55905 , USA. ${ }^{3}$ Department of Preventive Medicine, John D. Bower School of Population Health, University of Mississippi Medical Center, Jackson, MS 39216, USA. ${ }^{4}$ Cancer Institute, School of Medicine, University of Mississippi Medical Center, Jackson, MS 39216, USA. ${ }^{5}$ Institute for Bioengineering of Catalonia (IBEC), The Barcelona Institute of Science and Technology (BIST), 08028 Barcelona, Spain. ${ }^{6}$ Department of Experimental Pathology, Mayo Clinic, Rochester, MN 55905, USA. ${ }^{7}$ Girona Biomedical Research Institute, 17190 Salt, Girona, Spain. ${ }^{8}$ Program Against Cancer Therapeutic Resistance (ProCURE), Metabolism \& Cancer Group, Catalan Institute of Oncology, 17007 Girona, Spain. ${ }^{9}$ Deparment of

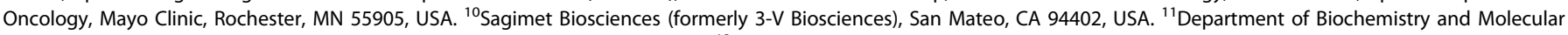
Biology Laboratory, Mayo Clinic Laboratory, Rochester, MN 55905, USA. ${ }^{12}$ Present address: Helmholtz Pioneer Campus, Heimholtz Zentrum München, Deutsches

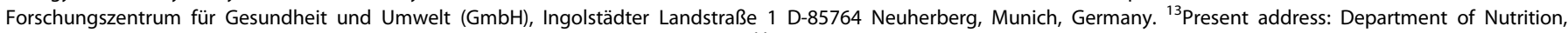

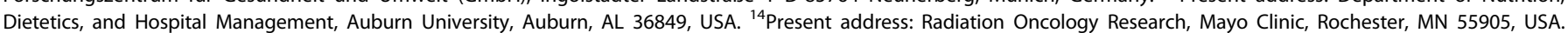

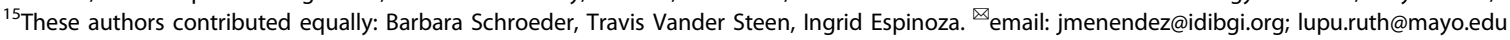
Edited by Dr Jean-Ehrland Ricci
}

Received: 10 March 2021 Revised: 12 September 2021 Accepted: 24 September 2021

Published online: 21 October 2021 


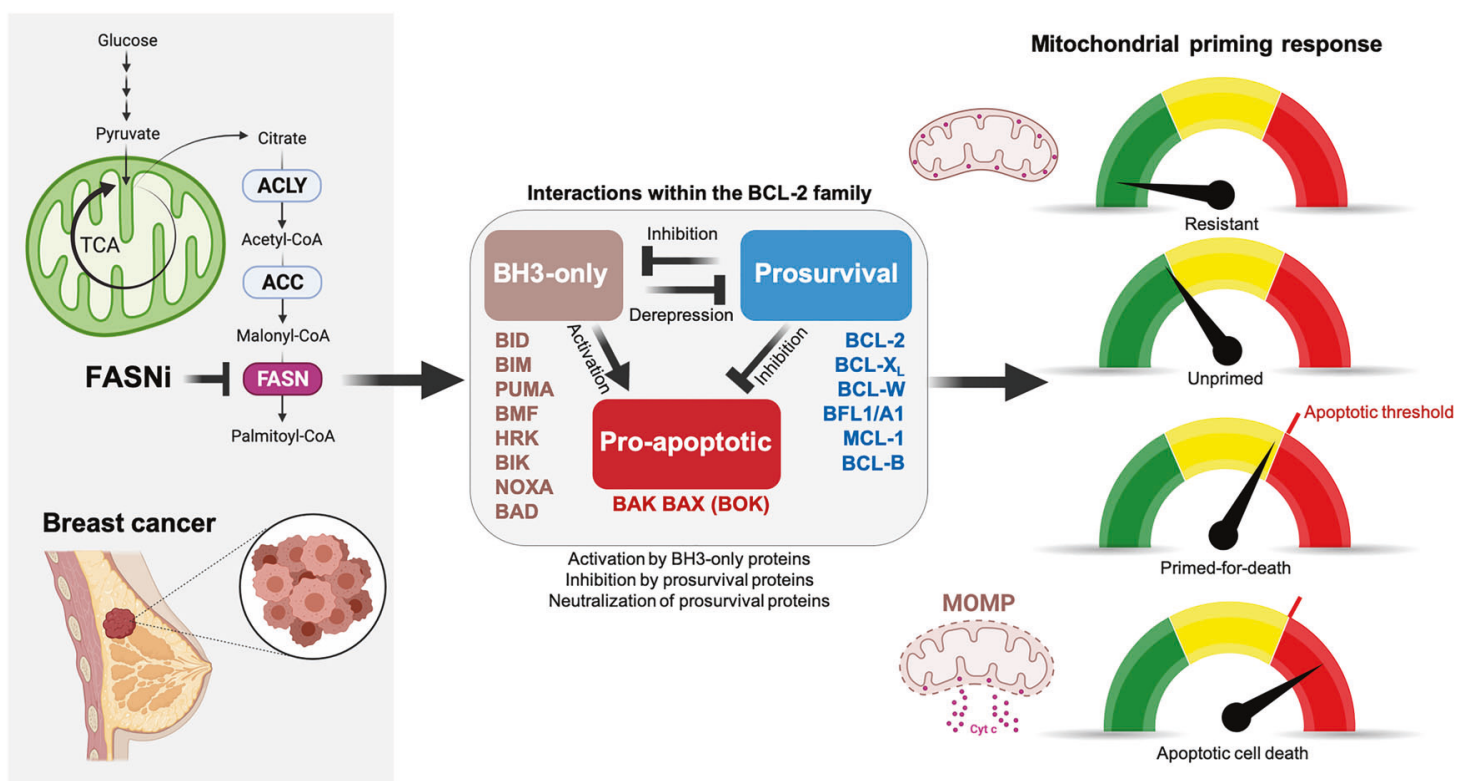

Fig. 1 FASN and the cell death decision circuitry controlled by the BCL-2 family. We envisioned that the functional interaction between FASN-catalyzed endogenous fatty acid biogenesis and the BCL-2 family interaction network that controls the mitochondrial pathway of apoptosis might be the basis for the differential sensitivity to FASN inhibitors (FASNis). The BCL-2 family can be divided into three classes, namely the pro-apoptotic BAX/BAK proteins, the proapoptotic BH3-only proteins, and the pro-survival proteins, the latter inhibiting the activity of the pro-apoptotic BCL-2 family members. Although historically those BH3-only proteins able to directly activate BAX/BAK have been termed either "activators" and those targeting pro-survival proteins to indirectly activate BAX/BAK have been called "sensitizers", this strict categorization is no longer appropriate as some "sensitizers" can exhibit direct activation functions under certain circumstances. Thus, BH3only proteins can be better distinguished by their ability to either directly bind and "activate" BAX/BAK or indirectly "derepress" pro-survival proteins (via hindering the ability of pro-survival proteins to sequester BH3-only proteins to stop them activating BAX/BAK or impeding the ability of pro-survival proteins to bind to activated BAX/BAK and prevent their homo-oligomerization). BAX/BAK activation ultimately controls mitochondrial outer membrane permeabilization (MOMP), which precedes the release of mitochondria-stored cytochrome $c$ (Cyt $c$ ) into the cytosol to promote apoptosome formation, subsequent activation of effector caspases, and apoptosis. The balanced interactions within the $\mathrm{BCL}-2$ family involving activation of $\mathrm{BH}$-only proteins and inhibition by pro-survival proteins lastly sets how close a cell is to the threshold or apoptosis, a property called "mitochondrial priming". Lack or low levels of activating/de-repressing events upon exposure to FASNis might lead to a resistant or unprimed state. When FASN blockade drives a high mitochondrial priming, cancer cells might acquire a primed-for-death state in which they ensure their survival by becoming "addicted" to anti-apoptotic proteins sequestering pro-apoptotic members. Created with BioRender.com.

FASNis-TVB-2640 [11] - has reignited interest in FASN as a target for new drug development. Unfortunately, the molecular determinants of cancer cell sensitivity to FASNis are unclear, mostly because the biological mechanisms responsible for FASNisinduced cell death are largely unknown [8-14]. Cancer cells can satisfy their demand for FAs by active uptake from the bloodstream [15], and the requirement of FASN in malignant transformation would be unrelated to its capacity to cellautonomously generate endogenous lipids [16]. FASN activity accounts for the highest cell consumption of not only NADPH but also acetyl-CoA [8], thereby unlocking IDH1-dependent reductive carboxylation to ensure the production of reduced equivalents to counterbalance the mitochondrial oxidative stress and overcome anoikis [17-20]. Whether the essentiality of FASN to generate the necessary reductive power to quench an excessive production of reactive oxygen species (ROS) might similarly explain why FASNis ultimately determine if the mitochondrial apoptotic pathway is activated or not [21-25] remains unexplored.

Here, we hypothesized that the intrinsic variability of cancer cells to promote mitochondrial oxidative stress and engage the death decision circuitry controlled by BCL-2 family interactions centrally contributes to the response to FASNis (Fig. 1). We now uncover a novel FASN-driven facet of the so-called "mitochondrial priming" that mechanistically links the redox-buffering mechanism of FASN activity to the intrinsic apoptotic threshold in cancer cells. We demonstrate that cancer cells treated with FASNis can acquire a "primed-for-death" mitochondrial state with apoptotic hypersensitivity to BCL-2 specific BH3-mimetics. The discovery that starvation of endogenously produced FAs is a metabolic stress that heightens mitochondrial apoptotic priming might open a new avenue to rationally use next-generation FASNis and $\mathrm{BH} 3$ mimetic drugs for combinatorial optimization in cancer therapy.

\section{MATERIALS AND METHODS}

\section{Cell lines}

The breast cancer cell lines BT-474, MDA-MB-231, and MCF-7 were obtained from the ATCC and were maintained in IMEM (Cellgro, Mediatech Inc., Manassas, VA) supplemented with $5 \%$ fetal bovine serum (FBS, Atlanta Biologicals, Lawrenceville, $\mathrm{GA}$ ) at $37^{\circ} \mathrm{C}$ in a humidified $5 \% \mathrm{CO}_{2}$ atmosphere. Cells were authenticated to ensure their identity using a short tandem repeat profiling method provided by the Genotyping Shared Resource at Mayo Clinic Rochester. HAP1 and HAP1 FASN-KO cells (\#HZGHC003700c006) were obtained from Horizon Discovery Ltd. (Cambridge, UK) and maintained at $37^{\circ} \mathrm{C}$ with $5 \% \mathrm{CO}_{2}$ in IMDM medium (Gibco) supplemented with $10 \% \mathrm{FBS}, 2 \mathrm{mmol} / \mathrm{L}$ L-glutamine, and $100 \mathrm{IU} / \mathrm{mL}$ penicillin/streptomycin. Cells were tested to confirm the absence of mycoplasma using the MycoAlert Mycoplasma Detection Kit (Lonza, Walkersville, MD).

\section{Reagents}

Reagents were purchased from the following suppliers: C75 (\#2489) from Tocris Bioscience (Minneapolis, MN); ABT-263/navitoclax (\#A3007) from APExBio (Houston, TX); ABT-199/venetoclax (\#CT-A199) from ChemieTek (Indianapolis, IN); TVB-3166 (\#SML1694) from Sigma-Aldrich (St. Louis, MO); S63845 (\#HY-100741) and A1331852 (\#HY-19741) from MedChemExpress (Monmouth Junction, NJ); TVB-3664 was provided by 3V-Biosciences/Sagimet Biosciences (San Mateo, CA); allophycocyanin (APC)-conjugated annexin V and binding buffer from BD Biosciences (San Diego, CA); CHAPS, propidium iodide, 
dimethyl pimelimidate, leupeptin, pepstatin, microcystin, sodium vanadate, $\mathrm{NaF}, \mathrm{NAC}$, cerulenin and protein A-Sepharose from Sigma-Aldrich (St. Louis, MO). The p38 inhibitor SB203580 (\#5633) and the JNK inhibitor SP600125 (\#42011-925MG) were purchased from Cell Signaling Technology Inc. (Danvers, MA) and Fisher Healthcare (Waltham, MA), respectively. Anti-BAK (\#12105), anti-BAX (\#2772), anti-BCL-2 (\#2872), anti-BCL-X (\#2762), anti-MCL-1 (\#45725), and anti-BIM (\#2819) antibodies were purchased from Cell Signaling Technology, Inc. (Danvers, MA). Anti-FASN antibody (\#610963) was purchased from BD Transduction Laboratories ${ }^{\mathrm{TM}} / \mathrm{BD}$ Biosciences (San Jose, CA). Anti-NOXA antibody (\#114C307, \#OP180) was purchased from Merck/Sigma-Aldrich. AntiPUMA (\#28226) and $\beta$-actin (\#1615 and \#66009) were purchased from Santa Cruz Biotechnology, Inc. (Santa Cruz, CA).

\section{Constitution of palmitate-bovine serum albumin (BSA) and BSA-C75 complexes}

Palmitate (Sigma-Aldrich) was complexed with BSA. Palmitate was dissolved in ethanol to $150 \mathrm{mmol} / \mathrm{L}$ and diluted $1: 5$ in a $4 \%(\mathrm{w} / \mathrm{v}) \mathrm{BSA}$ solution in $0.9 \% \mathrm{NaCl}$ and incubated for $1 \mathrm{~h}$ at $37^{\circ} \mathrm{C}$ to obtain a $30 \mathrm{mmol} / \mathrm{L}$ stock of BSA-complexed palmitate. C75 was then incubated with different concentrations of palmitate-BSA complex for $9 \mathrm{~h}$ at $37^{\circ} \mathrm{C}$ and used for experiments.

\section{Annexin V binding by flow cytometry}

Binding of APC-conjugated annexin $\mathrm{V}$ to cells was assessed by flow cytometry. 20,000 events of pooled adherent and floating cells were collected from the FL3 (excitation $488 \mathrm{~nm}$, emission 650 LP) and FL4 (excitation $635 \mathrm{~nm}$, emission $661 \pm 8 \mathrm{~nm}$ ) channels of a Becton Dickinson Accuri C6 flow cytometer, and data were analyzed using Accuri C6Flow software.

\section{Assessment of intracellular ROS}

Intracellular ROS production was monitored using the permeable fluorescence dyes 5-(and-6)-carboxy-2,7-dichlorodihydrofluorescein diacetate (carboxy- $\mathrm{H}_{2} \mathrm{DCFDA}$ ) (Invitrogen) and dihydroethidine (DHE) (SigmaAldrich). Fluorescence intensity of intracellular DCF (excitation $488 \mathrm{~nm}$, emission $530 \mathrm{~nm}$ ) or ethidium (excitation $488 \mathrm{~nm}$, emission $585 \mathrm{~nm}$ ) was measured and analyzed by flow cytometry using Accuri C6Flow software.

\section{Mitochondrial membrane potential}

Changes in $\Delta \psi_{\mathrm{m}}$ were estimated using a flow cytometer-based analysis method for the JC-1 probe (Molecular Probes protocol: MitoProbe JC-1 assay kit for flow cytometry).

\section{Cytochrome c release assay}

Cytochrome $c$ release was assayed using the InnoCyte ${ }^{\mathrm{TM}}$ Flow Cytometry Cytochrome c Release Kit (Calbiochem, Los Angeles, CA).

\section{Determination of NADPH/NADP ${ }^{+}$ratio}

The NADPH/NADP ${ }^{+}$ratio was assessed using an $\mathrm{NADP}^{+} / \mathrm{NADPH}$ quantification kit (BioVision, Mountain View, CA).

\section{Western blot analysis}

Cells were harvested and lysed in $1 \times$ cell lysis buffer (Cell Signaling Technology) containing protease and phosphatase inhibitors (Roche, Indianapolis, IN) on ice for $30 \mathrm{~min}$ with recurrent mixing every $5 \mathrm{~m}$. Protein concentrations were determined using the Pierce BCA protein assay kit (Pierce, Rockford, IL). Cell lysates aliquots were resolved on 4-15\% polyacrylamide gels (Criterion TGX precast Gel; Bio-Rad, Hercules, CA) and transferred to PVDF membranes. Membranes were blocked with 5\% BSA for $1 \mathrm{~h}$ at RT and incubated with primary antibodies overnight at $4^{\circ} \mathrm{C}$. Membranes were washed 3 times with TBS-T, incubated with horseradish peroxidaselinked secondary antibodies $(1: 4,000)$ for $1 \mathrm{~h}$ at $\mathrm{RT}$, and visualized using enhanced chemoluminescence reagent (Pierce) and Hyperfilm.

Quantitative reverse transcriptase-polymerase chain reaction RNA was isolated using the Qiagen RNEasy plus mini kit. Analysis was performed in triplicate using RNA (100 ng) and TaqMan One-Step RT-PCR Master Mix (Applied Biosystems, Carlsbad, CA). Probe sets were: Noxa (Hs00560402_m1), Bim (Hs00197982_m1), Puma (Hs00248075_m1), Bid (Hs00609632_m1), Bik (Hs00154189_m1), Bax (Hs00180269_m1), Bak (Hs00832876_g1), BCl-2 (Hs00608023_m1), BCl- $x_{L}\left(\mathrm{Hs} 00236329 \_m 1\right)$, and
Mcl-1 (Hs03043898_m1). PCR was performed on the ABI Prism 7900HT realtime system using a program consisting of $48^{\circ} \mathrm{C}$ for $30 \mathrm{~min}, 95^{\circ} \mathrm{C}$ for $10 \mathrm{~min}$, then 40 cycles of $95^{\circ} \mathrm{C}$ for $15 \mathrm{~s}$ and $60^{\circ} \mathrm{C}$ for $1 \mathrm{~min}$. Data analyses were performed using the following equations: $\Delta C_{\mathrm{t}}=C_{\mathrm{t}}$ (sample) $-C_{\mathrm{t}}$ (endogenous control); $\Delta \Delta C_{\mathrm{t}}=\Delta C_{\mathrm{t}}$ (sample) $-\Delta C_{\mathrm{t}}$ (untreated); and fold change $=2-\Delta \Delta C_{\mathrm{t}}$.

\section{Small interfering RNA (siRNA) transfection}

RNA interference was performed using siRNAs directed against: Noxa (5'GGAGAUUUGGAGACAAACU-3'), Puma (5'-GCCUGUAAGAUACUGUAUA-3'), or Bim (5'-GACCGAGAAGGUAGACAAU-3'), all from Ambion (Austin, TX). On day one, $1 \times 10^{7}$ cells were suspended in $370 \mu \mathrm{L}$ of medium containing $1 \mathrm{mmol} / \mathrm{L}$ oligonucleotides and subjected to electroporation using a BTX 830 square wave electroporator (BTX, San Diego, CA) delivering a single pulse at $200 \mathrm{mV}$ for $10 \mathrm{~m}$. Twenty-four hours after transfection, cells were treated with diluent or $\mathrm{C} 75$ for an additional $48 \mathrm{~h}$ and then assayed for annexin $\mathrm{V}$ binding by flow cytometry.

\section{Dynamic BH3 profiling}

Dynamic $\mathrm{BH} 3$ profiling experiments were performed as previously described [26-28].

\section{Cell viability assays}

Cell viability effects were determined using the standard colorimetric MTT reduction assay.

\section{Xenograft studies}

Xenografts were established by injecting $2 \times 10^{6}$ BT-474 cells subcutaneously into ovariectomized 3- to 4-week-old athymic female nude-Doxn $1^{\text {nu }}$ mice (Harlan Sprague Dawley, Madison, WI) subcutaneously implanted with slowrelease estrogen pellets (Innovative Research) around left forearm using a trocar. Once tumor engraftment was confirmed $\left(>100 \mathrm{~mm}^{3}\right)$, mice $(n=10$ per group) were randomly allocated to each of the following treatment groups: Group A: (i.) Vehicle (PEG-400), (ii.) TVB-3664 (2 mg/kg/day/oral), (iii.) ABT-199 (100 mg/kg/ day/oral), and (iv.) TVB-3664 (2 mg/kg/day/oral) + ABT-199 (100 mg/kg/day/oral); group B: (i.) Vehicle (PEG-400), (ii.) TVB-3664 (2 mg/kg/day/oral) alone, (iii.) ABT263 (100 mg/kg/day/oral) alone, and (iv.) TVB-3664 (2 mg/kg/day/oral) + ABT263 (100 mg/kg/day/oral). For oral dosing, TVB-3664 was formulated in 100\% PEG-400 and diluted with water to a final PEG concentration of $30 \%$ immediately before dosing. Tumor volume was calculated by 3D measurements using the formula: tumor volume $\left(\mathrm{mm}^{3}\right)=($ length $\times$ width $\times$ height $) / 2$. Tumor volume values (mean \pm S.D.) were calculated weekly over a 4 week-period for each experimental group using a Vernier caliper.

\section{Statistical analysis}

At least three independent experiments were performed with $n \geq 3$ replicate samples per experiment. Data are presented as mean \pm S.D. Student's $t$ test was used to compare the means between two groups; comparisons of means of $\geq 3$ groups were performed by one-way ANOVA and Dunnett's $t$-test for multiple comparisons using GraphPard Prism (GraphPad Software, San Diego, CA). $P$-values $<0.05$ and $<0.005$ were considered to be statistically significant (denoted as ${ }^{*}$ and ${ }^{* *}$, respectively). All statistical tests were two-sided.

\section{RESULTS}

The extent of FASN inhibition-induced apoptotic cell death relates to FASN expression status

We first examined apoptotic cell death using the semi-synthetic FASNi C75 in three breast cancer cellular models expressing distinct levels of FASN: BT-474 "> MCF-7 > MDA-MB-231 (Fig. 2a, inset). C75 significantly and dose-dependently increased the number of annexin V-positive BT-474 cells relative to vehicle-treated control cells (Fig. 2a). A drastically smaller but still significant increase in annexin V-positive cells was observed in C75-treated MCF-7 and MDA-MB-231 cells. Equivalent findings were found when using the natural FASN inhibitor cerulenin (Fig. S1a).

\section{FASN inhibition promotes ROS-dependent mitochondrial} cytochrome $c$ release during apoptosis

We assessed whether FASN inhibition was accompanied by changes in two apoptosis-related readouts, namely mitochondrial 
a

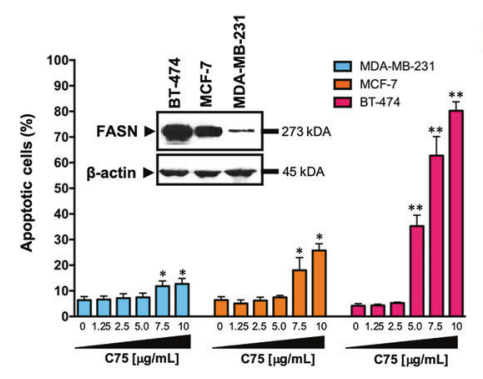

b

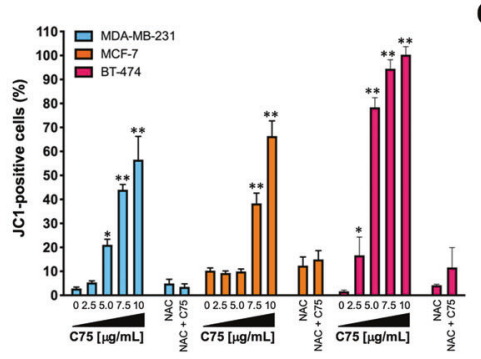

C

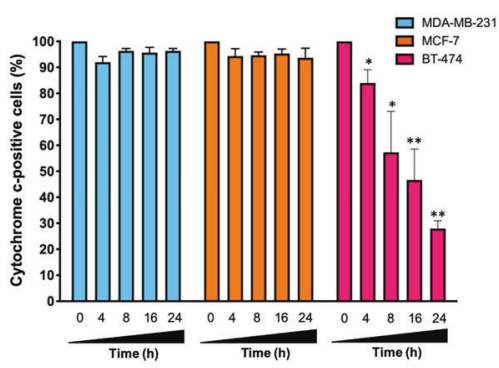

d
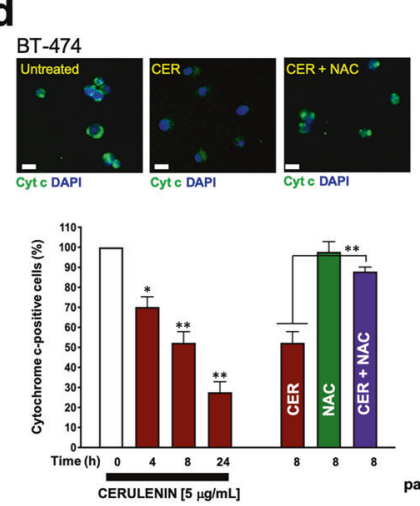

-

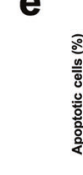
$\mathrm{C} 75[7.5 \mathrm{\mu g} / \mathrm{mL}]$
$\mathrm{NAC}[5 \mathrm{mmol} / \mathrm{L}]$
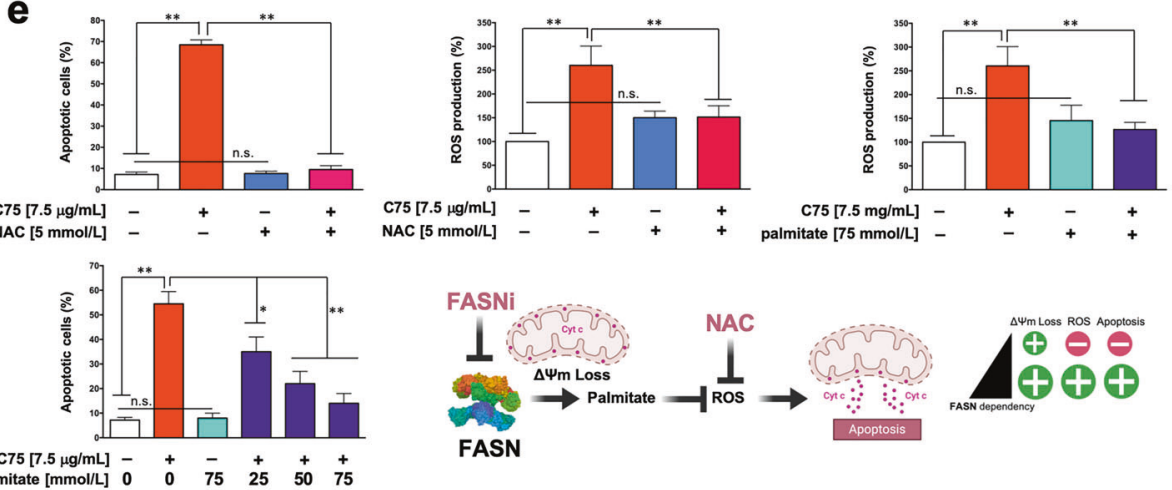

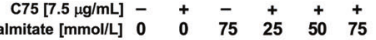

Fig. 2 FASN inhibition promotes high levels of apoptotic cell death in FASN-overexpressing breast cancer cells. a. BT-474, MCF-7, MDAMB-231 cells were treated with graded concentrations of C75 or vehicle (DMSO) for $48 \mathrm{~h}$ and apoptosis was evaluated by annexin V/ propidium iodide staining using two-color flow cytometry. The inset shown the expression of FASN protein in the three cell lines. $\mathbf{b}$ Flow cytometry assessment of JC-1 fluorescence in cells treated with graded concentrations of C75 or vehicle (DMSO) for $48 \mathrm{~h}$. Alternatively, cells were treated with $7.5 \mu \mathrm{g} / \mathrm{mL} \mathrm{C75}$ in the absence or presence of $5 \mathrm{mmol} / \mathrm{L} \mathrm{N}$-acetylcysteine (NAC). c Flow cytometry-based assessment of mitochondrial cytochrome c following exposure to C75 $(7.5 \mu \mathrm{g} / \mathrm{mL})$. d Top. Representative immunofluorescence images of cytochrome $c$ staining in BT-474 cells treated with cerulenin in the absence or presence of N-acetylcysteine (NAC). Scale bar is $10 \mu \mathrm{m}$. Bottom. Flow cytometry-based assessment of mitochondrial cytochrome $c$ following exposure to cerulenin in the absence or presence of NAC. e Left. Quantification of apoptosis and reactive oxygen species (ROS) in BT-474 cells treated with C75 in the absence or presence of NAC or palmitate. Right. Mitochondrial depolarization appears to be a common response to FASN inhibition irrespective of FASN status; however, the FASNidriven decrease in $\Delta \psi_{\mathrm{m}}$ levels appears to have to reach a certain threshold to elicit the release of mitochondrial cytochrome $\mathrm{c}$ accompanying apoptotic cell death, which is restricted to FASNi-sensitive cancer cells in an apparently ROS-dependent manner. All data are presented as mean \pm SD $(n=3), p<0.05$ and $p<0.005$ ( $^{*}$ and ${ }^{*}$, respectively).

transmembrane potential $\left(\Delta \psi_{\mathrm{m}}\right)$ and cytochrome c release [29-32]. All three cell lines responded to C75 with a dose-dependent increase in the number of cells positive for JC-1 green fluorescence (Fig. 2b), indicating mitochondrial membrane depolarization. C75-induced loss of $\Delta \psi_{m}$ was prevented by $N$-acetylcysteine (NAC) $[33,34]$ (Fig. 2b), suggesting a role for ROS in the loss of $\Delta \psi_{\mathrm{m}}$ upon FASN blockade. ROS production was significantly increased by C75 in BT474 and MCF-7 cells, but not in MDA-MB-231 cells, as revealed by DCF staining (data not shown).

A time-dependent release of cytochrome c was observed only in FASNis-treated BT-474 cells but not in MCF-7 and MDA-MB-231 cells, as measured by flow cytometry (Fig. 2c, d). Co-treatment with NAC treatment blocked the ability of the FASNi to induce apoptotic cell death (Fig. 2e, Fig. S1b), and prevented ROS production and cytochrome c release in FASNis-sensitive cancer cells (Fig. 2d, e). Co-treatment with the FASN end-product palmitate largely prevented C75-induced ROS production and effectively protected BT-474 cells from apoptosis in a dosedependent manner (Fig. 2e).

\section{FASN inhibition activates redox-sensing kinases}

As ROS production commonly results from redox stress, and considering that redox-associated NADPH is rapidly consumed by FASN [24], we examined the effects of FASN inhibition on NADPH accumulation. We found a dramatic, dose-dependent accumulation of NADPH in BT-474 cells treated with C75 (Fig. S1c). C75 promoted a more modest increase in the NADPH/NADP ${ }^{+}$ratio in both MCF-7 and MDA-MB-231 cells (Fig. S1c).
Redox imbalance causes the activation of stress-related proapoptotic kinases such as Jun N-terminal kinase (JNK) and p38 mitogen-activated protein kinase (p38 MAPK) $[35,36]$. Although with different activation dynamics that might reflect the induction of stress responses to attenuate ROS-mediated JNK activation, FASNi augmented the phosphorylation status of both JNK and p38 MAPK, which was largely prevented by NAC (Fig. S1d). FASN inhibition also strongly activated AMP-activated protein kinase (AMPK), a key regulator of metabolism and survival during energy stress that senses intracellular redox signals [37], and this was prevented by NAC (Fig. S1d).

\section{FASN inhibition upregulates pro-death BH3-only proteins}

Using pooled populations of both adherent and dead floating cells, we found that the expression of the multidomain antiapoptotic proteins $B C L-2, B C L-X_{L}$, and $M C L-1$ remained mostly unchanged following pharmacological inhibition of FASN activity (Fig. 3a, S1e). C75 treatment resulted in a robust dose-dependent upregulation of the BH3-only BCL2 members BIM, NOXA, and PUMA at both protein and mRNA levels (Fig. 3a). Inhibition of p38 MAPK activity with SB203580 lessened the ability of C75 to upregulate BIM, NOXA, and PUMA (Fig. S1f, g), indicating that ROSdriven activation of stress-induced kinases is linked to the induction of $\mathrm{BH} 3$-only proteins in FASN-inhibited cancer cells. The protein synthesis inhibitor cycloheximide blocked the activation of BH3-only proteins in C75-treated cells (Fig. S1f, g), suggesting that their accumulation after FASN inhibition requires de novo protein synthesis. 

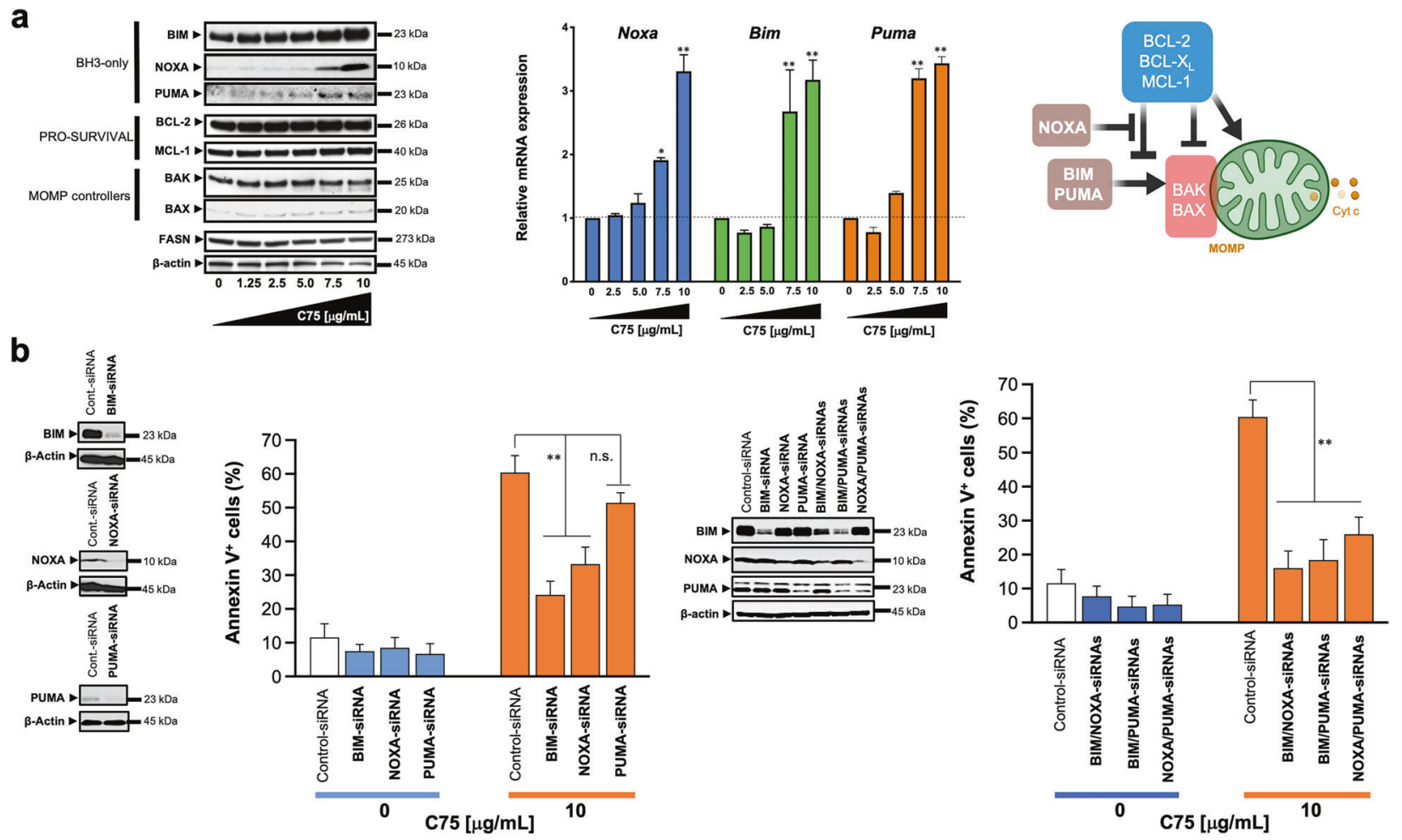

Fig. 3 BH3-only proteins mediate FASN inhibition-induced apoptosis. a FASN inhibition activates pro-apoptotic BH3-only proteins. Left. Representative immunoblot analysis of NOXA, BIM, PUMA, BAK, BAX, BCL-2, MCL-1, and FASN in cell lysates from BT-474 cells treated with graded concentrations of C75 for $48 \mathrm{~h}$. Right. Q-PCR analyses of the expression of Bim, Noxa, and Puma. Before RNA extraction, cells were treated with C75 in the presence of the pan caspase inhibitor Q-VD-OPh $(5 \mu \mathrm{mol} / \mathrm{L})$ for $48 \mathrm{~h}$, collected by trypsinization, sedimented at $250 \times g$ for $10 \mathrm{~min}$ and frozen on dry ice. Data are presented as mean $\pm \mathrm{SD}(n=3), p<0.05$ and $\mathrm{p}<0.005(*$ and **, respectively). b. Depletion of BH3only proteins prevents FASNi-induced apoptotic cell death. Annexin V/propidium iodide staining-based flow cytometric assessment of apoptotic cell death in C75-treated BT-474 cells previously transfected with either control, BIM, NOXA, or PUMA single siRNAs (top panels) or their combinations (bottom panels). Annexin $\mathrm{V}^{+}$cells data are presented as mean \pm SD $(n=3), p<0.05$ and $p<0.005$ ( ${ }^{*}$ and ${ }^{* *}$, respectively). Also shown are representative immunoblots $(n=3)$ of the BIM, NOXA, and PUMA knockdown efficiencies achieved by the corresponding SiRNAs.

siRNA-mediated knockdown of BIM or NOXA significantly reduced (up to 60 and $40 \%$ reduction, respectively) apoptotic cell death in C75-treated BT-474 cells (Fig. 3b). siRNA-mediated depletion of PUMA had less significant effect on C75-induced apoptosis. Although those combinations containing the BIM-targeted siRNA (BIM/NOXA and BIM/PUMA) were the most effective in preventing C75-induced apoptotic cell death, the dual NOXA/PUMA silencing was also capable of significantly reducing the extent of apoptosis in FASNinhibited cells (Fig. 3b). Palmitate rescued the downregulation of FASN expression and the upregulation of BIM, NOXA, and PUMA in response to C75 (Fig. S1h).

\section{FASN status is a cancer cell-intrinsic determinant of mitochondrial priming}

FASN activity might regulate cancer cell survival by fine-tuning the mitochondrial threshold for apoptosis, known as "mitochondrial priming" [38-47]. To test this hypothesis, we took advantage of the human near-haploid cell line HAP1 and its isogenic derivative carrying a loss-of-function mutation in FASN as a suitable model system for defective de novo FA synthesis [48]. We envisioned that CRISPR/Cas9-mediated specific suppression of FASN might suffice to drive early changes in the $\mathrm{BCL}-2$ family of proteins preceding the apoptotic process engagement, which can be detected by the dynamic BH3 profiling assay $[38,39,45]$. The more "primed" a cell is, the more sensitive its mitochondria will be to the synthetic BIM BH3 peptide, which promiscuously binds to all the anti-apoptotic BCL-2 family members and is a probe of overall mitochondrial priming. The half-maximal concentration of the BIM peptide required to promote cytochrome $c$ release decreased by $\sim 3$-fold in FASN-KO cells compared to FASN-expressing isogenic counterparts (Fig. 4a, left), revealing that the $\mathrm{BIM} \mathrm{BH} 3$ peptide permeabilized the mitochondria more efficiently upon FASN depletion. Accordingly, FASN-KO cells exhibited a $\Delta \%$ priming of $\sim 23 \%$ at $0.1 \mu \mathrm{mol} / \mathrm{L}$ BIM BH3 peptide. An equivalent $\Delta \%$ priming occurring in HAP1 cells treated with a suboptimal concentration of the FASNi C75 $(5 \mu \mathrm{g} / \mathrm{mL})$ was largely prevented in FASN-KO HAP1 cells (Fig. 4a, left).

\section{FASN inhibition enhances sensitivity to the BCL-2 family inhibitor navitoclax/ABT-263}

If FASN suppression elicits an enhanced mitochondrial priming response, then FASNis should overcome resistance to $\mathrm{BH} 3$ mimetics (Fig. 4a, right). We first questioned whether cancer cells treated with C75 showed increased sensitivity to $\mathrm{BH} 3$ mimetic drugs such as the dirty/promiscuous antagonist of $\mathrm{BCL}-2, \mathrm{BCL}-\mathrm{X}_{\mathrm{L}}$, and $\mathrm{BCL}-\mathrm{W}$ navitoclax/ABT-263 [49, 50]. Whereas single-agent navitoclax failed to trigger apoptotic cell death, addition of C75 noticeably synergized (2-3-fold) with navitoclax/ABT-263 (Fig. 4b). This ability involved a synergistic amplification of ROS generation (Fig. S1i). In SKBR-3 cells, which express the highest cellular levels of FASN (up to $28 \%$ by weight of the cytosolic proteins) yet described in human established cell lines [26, 27, 51, 52], a clear apoptotic synergism was observed when C75 was added to navitoclax/ABT-263, which had no impact against SKBR-3 cells as single agent (Fig. 4b). The apoptosis-resistant phenotype of low/moderate-FASN expressing MDA-MB-231 and 
a
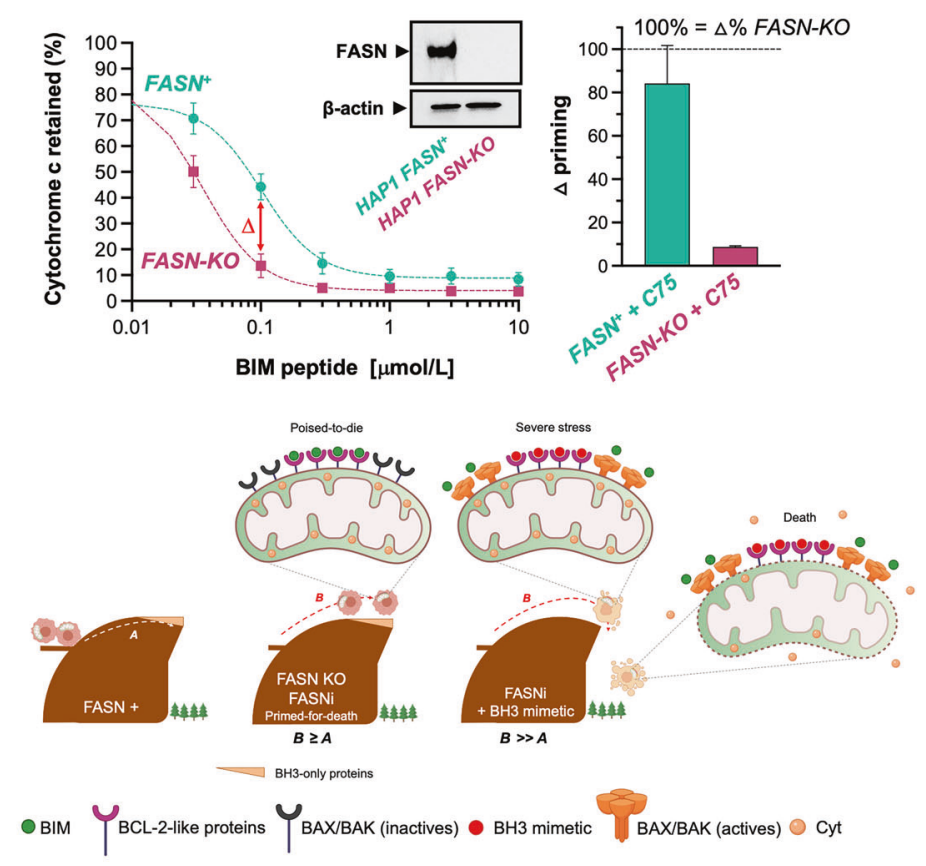

b

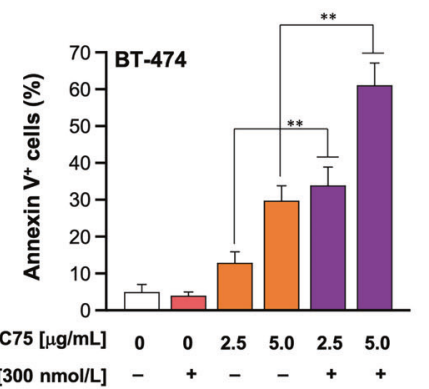

ABT-263 [300 nmol/L] - +

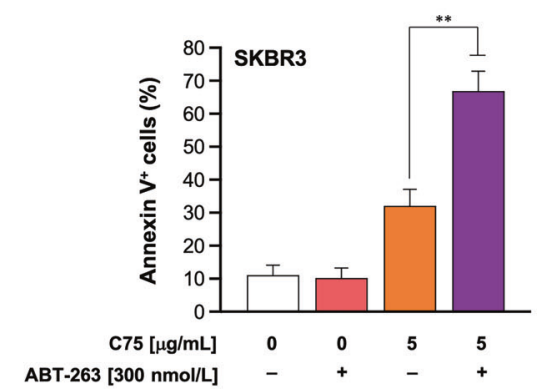

C

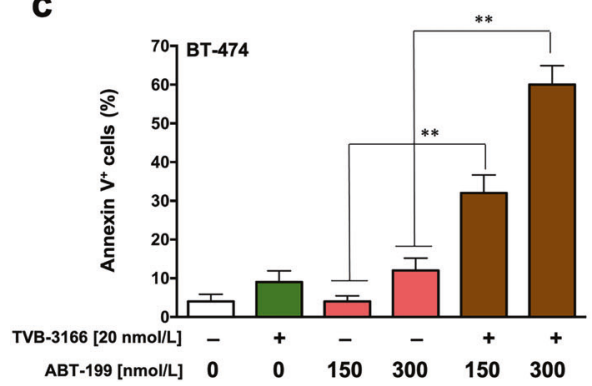

d

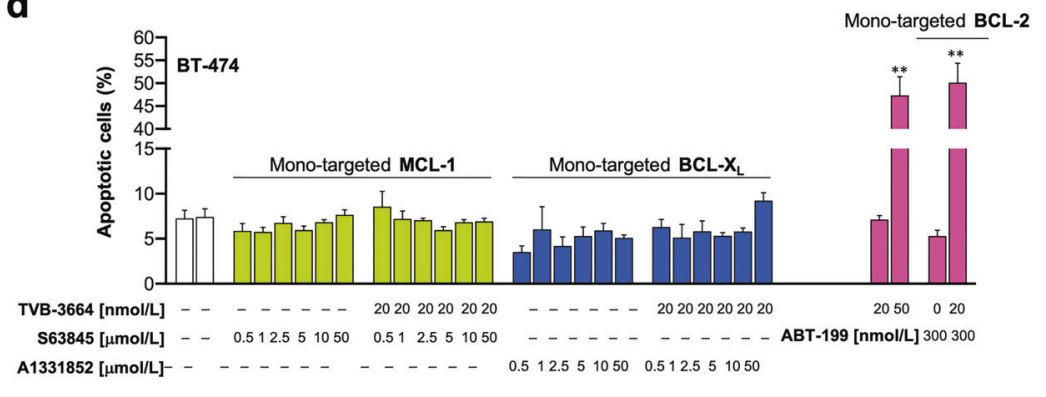

Fig. 4 FASN inhibition exacerbates the pro-apoptotic activity of BCL2-targeting BH3 mimetics. a FASN is a determinant of mitochondrial priming. Left. Dynamic BH3 profiling (DBP) assay of $F A S N$-expressing HAP1 parental cells and HAP1 FASN-KO isogenic derivatives after treatment with increasing concentrations of the BIM BH3 peptide. Representative immunoblot analysis of FASN in cell lysates from HAP1 FASN ${ }^{+}$parental cells and HAP1 FASN-KO isogenic derivatives. Results expressed as $\Delta \%$ priming represents the increase in priming compared to FASN-containing HAP1 control cells. $\Delta \%$ priming after $16 \mathrm{~h}$ incubation with C75 was measured by enhanced BIM-induced cytochrome $c$ release compared to DMSO-treated controls. Data are presented as mean \pm SD $(n=4)$. Right. Mitochondrial priming is depicted as proximity to the "cliff's edge" (i.e., the apoptotic threshold). FASN-expressing cells (FASN + ) are at distance $A$ from the edge. FASN suppression/inhibition causes mitochondrial membrane depolarization (an early event in the onset of apoptosis). The distance that FASN inhibition pushes the cells towards the clifftop is represented by the movement $B$, which is sufficient to push the cells to the clifftop $(B \geq A)$. This model predicts that the ability of FASN-inhibited cells to cross the apoptotic threshold and fall to the "cell death valley" can be accelerated in the presence of BH3 mimetics, which promote a deepening of the slope towards the valley $(B » A)$. Created with BioRender.com. $\mathbf{b}, \mathbf{c}$, $\mathbf{d}$ Annexin V/propidium iodide staining-based flow cytometric assessment of apoptotic cell death in BT-474 and SKBR3 cells treated with FASNis (C75, TVB-3166, TVB-3664) in the absence or presence of ABT-263, ABT-199, S63845, and A-1331852. Representative experiments showing the percentage of annexin V-positive cells in each experimental condition and quantification of apoptosis are shown. Data are presented as mean \pm SD $(n=3), p<0.05$ and $p<0.005$ (* and ${ }^{* *}$, respectively).

MCF-7 treated with navitoclax/ABT-263 remained unaltered by the addition of C75 (Fig. S1j).

\section{A clinical grade FASNi sensitizes cancer cells to the BCL-2- specific BH3 mimetic venetoclax/ABT-199 in vitro}

We explored the nature of the interaction between the recently developed small-molecule FASNi TVB-3166 [12] and venetoclax/ABT199, an FDA-approved BH3 mimetic that specifically targets BCL-2 rather than multiple BCL proteins [53-55] (Fig. 4c). HAP1 FASN-KO cells were largely refractory to the cytotoxic effects of TVB-3166 (Fig. S1k), thereby demonstrating the FASN-dependent mechanism of action of the TVB series of FASNis. Whereas single-agent venetoclax/ABT-199 failed to induce any significant level of apoptotic cell death, addition of TVB-3166 dramatically enhanced the capacity of venetoclax/ABT199 to promote apoptotic cell death in BT-474 cells (Fig. 4c).

To definitely delineate the right $\mathrm{BH} 3$ mimetic that should accompany a FASNi to work better in a clinical setting [56, 57], we finally examined the nature of the apoptotic interaction between mono-targeted BH3 mimetics and the TVB-3166-related molecule TVB-3664-a close analog of the clinical-grade FASNi TVB-2640 [56-61]. Co-administration of TVB-3664 synergistically augmented the apoptosis-inducing activity of the BCL-2 specific BH3-mimetic 
a
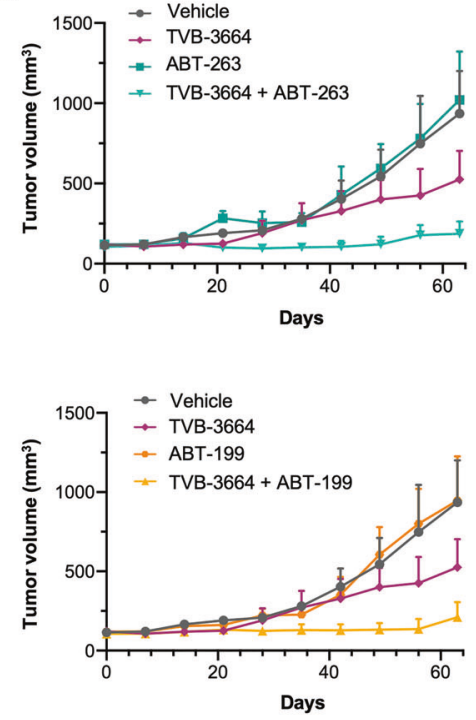

b
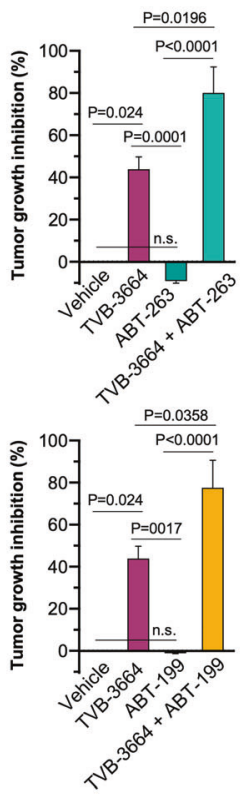
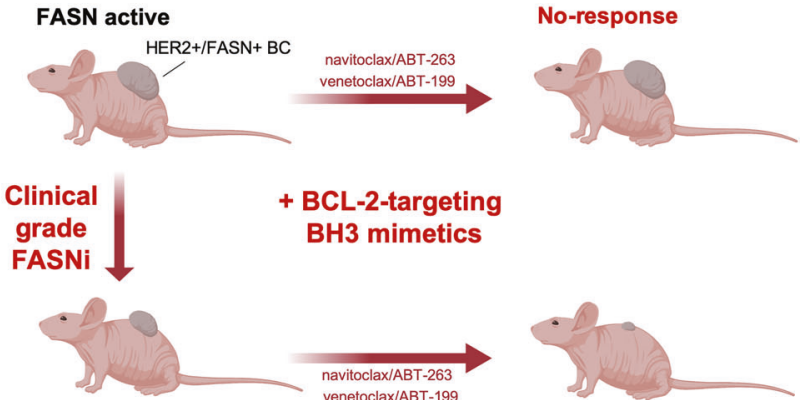

FASN blocked

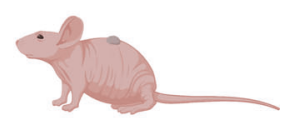

RESPONSE
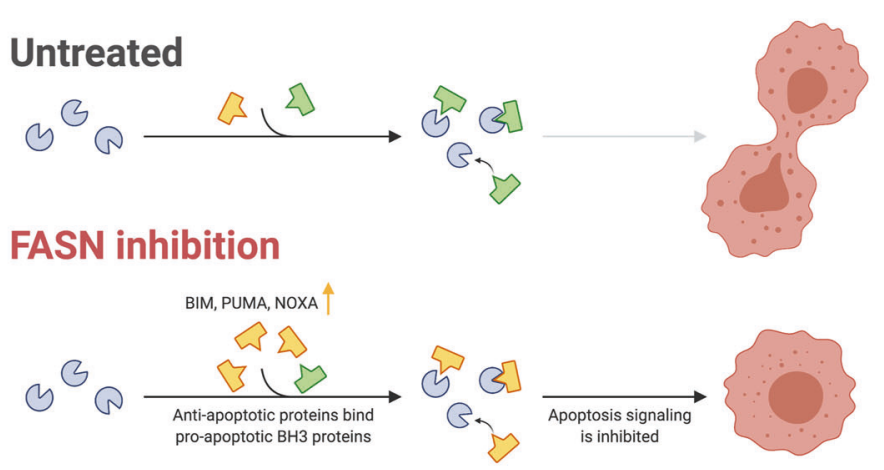

FASN inhibition + BH3 mimetics
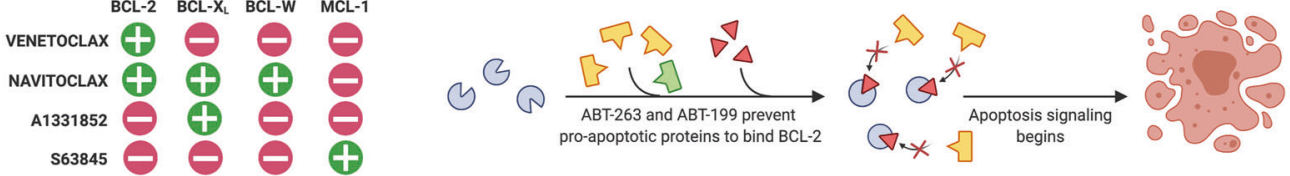

Fig. 5 FASN inhibition sensitizes human breast tumor xenografts to BCL-2-targeting BH3 mimetics. a Left. Growth of BT-474 xenograft tumors in athymic female mice treated with BH3 mimetics navitoclax/ABT-263 (top) and venetoclax/ABT-199 (bottom) in the absence or presence of the FASNi TVB-3664. The maximum length for each treatment was 63 days. Results are presented as the mean tumor volume \pm S. D. ( $n=10$ mice/experimental group). Tumor growth inhibition (TGI) was calculated as the percentage of tumor growth, relative to tumor size at the start of treatment, in drug-treated groups compared to vehicles-treated group. Right. In vivo findings from the HER2 + /FASNoverexpressing breast cancer model BT-474 uncovers a novel FASN-dependent mitochondrial priming that links de novo FA biosynthesis to the intrinsic apoptotic threshold in breast cancer cells. The discovery that FASN-inhibited cancer cells exist in an apoptosis-prone state highly sensitive to BCL-2-targeting BH3 mimetics might warrant clinical exploration in patients with HER2 + /FASN-addicted breast carcinomas (see the discussion section). FASN inhibition increases mitochondrial priming and enhances breast cancer cell sensitivity to BCL2-targeting BH3 mimetics: a working model (b). FASN-inhibited breast cancer cells exhibit an exacerbated apoptotic sensitivity to BH3 mimetics. In FASNaddicted cancer cells, FASNis promote increased levels of pro-apoptotic activators such as BIM, thereby poising these cells ready for apoptotic cell death. However, FASN-inhibited cells can survive with high mitochondrial priming because they become "addicted" to the expression of anti-apoptotic proteins such as BCL-2 to sequester BIM and ensure survival. Cancer cell death will occur if the sequestration capacity of antiapoptotic proteins is exceeded by levels of pro-apoptotic proteins, which can be pharmacologically achieved with $\mathrm{BH} 3$ mimetic drugs capable of disrupting the ability of anti-apoptotic BCL-2 family members to neutralize BH3-only proteins-driven activating events. Specifically, coadministration of a FASNi synergistically augments the apoptosis-inducing activity of the dual BCL- $\mathrm{X}_{\mathrm{L}} / \mathrm{BCL}-2$ inhibitor ABT-263 (navitoclax) and the BCL-2 specific BH3-mimetic ABT-199 (venetoclax). FASN inhibition, however, fails to sensitize breast cancer cells to MCL-1- and BCL- $\mathrm{X}_{\mathrm{L}}-$ selective inhibitors such as S63845 and A1331852. Adapted from "MCL-1 Inhibition for Leukemia Treatment" by BioRender.com (2021). Retrieved from https://app.biorender.com/biorender-templates. 
venetoclax/ABT-199 (Fig. 4d). TVB-3664, however, failed to sensitize breast cancer cells to BH3-mimetics mono-targeting MCL-1 (S63845) and BCL- $\mathrm{X}_{\mathrm{L}}$ (A1331852) (Fig. 4d) [62].

\section{A clinical grade FASNi enhances sensitivity to navitoclax/ABT- 263 and venetoclax/ABT-199 in vivo}

We finally sought to determine the efficacy of combining navitoclax/ABT-263 or venetoclax/ABT-199 with TVB-3664 against BT-474 human breast cancer xenografts in nude mice. BH3 mimetics and TVB-3664 were administered by oral gavage to mimic human oral drug administration. Both navitoclax/ABT-263 and venetoclax/ABT-199 failed to elicit any tumor growth delay of BT-474 xenograft tumors; notably, single agent TVB-3664 was notably efficacious in producing a tumor response (44\% tumor growth inhibition) (Fig. 5a). The completely lack of anti-tumor efficacy of navitoclax/ABT-263 and venetoclax/ABT-199 as single agents was fully circumvented when FASN activity was pharmacologically targeted in BT-474 tumor xenografts; thus, when administered in combination with the FASNi TVB-3664, navitoclax/ ABT-263 and venetoclax/ABT-199 caused strong tumor growth inhibition ( $80 \%$ and $78 \%$, respectively; Fig. 5a). Combination therapy appeared to be well-tolerated, with mice maintaining normal body weight (Fig. S1k).

\section{DISCUSSION}

A major roadblock to the clinical application of FASNis is that the mechanism behind the resistance versus sensitivity of cancer cells to death signaling triggered by FASN blockade remained poorly understood [11-14]. We here show the ability of FASN activity to dictate how close a cell is to the threshold of apoptosis, a property called mitochondrial priming [38-48]. Mitochondria in FASN-inhibited cancer cells exist in a primed-for-death state that offers a novel therapeutic opportunity to treat breast cancer by inducing hypersensitization to pro-apoptotic $\mathrm{BH} 3$ mimetic drugs (Fig. 5b).

The fate of cancer cells exposed to FASNis might depend on their proximity to an apoptotic threshold. Elevated levels of BCL-2like pro-survival proteins bound to pro-apoptotic family members (e.g., BIM) appear to prepare cancer cells for apoptosis following FASNi. Cell death induced by FASNis is diminished by concurrent loss of pro-apoptotic proteins, suggesting that FASN activity regulates cancer cell survival by fine-tuning the mitochondrial threshold for apoptosis. Thus, while FASNis may not overtly affect cancer cell viability, they heighten mitochondrial priming, which shifts cancer cells towards a primed-for-death state that is addicted to anti-apoptotic proteins to ensure survival but allows a BH3-mimetic to unleash the mitochondrial pathway of apoptosis. Specifically, counteracting the binding of proapoptotic proteins with BH3-mimetics antagonizing BCL-2 (navitoclax and venetoclax) rather than MCL-1 (S63845) and/or BCL- $\mathrm{X}_{\mathrm{L}}$ (A1331852) abolishes this protected state (Fig. 5b), leading to increased apoptosis in FASN-inhibited cancer cells.

$\mathrm{BCL}-2$-targeting $\mathrm{BH} 3$ mimetics alone have shown promising activity in hematological malignancies, but they have been mostly ineffective for solid tumors [63]. The response to $\mathrm{BH} 3$ mimetics requires the alteration of the proapoptotic/antiapoptotic balance of BCL-2 members through concomitant exposure to chemotherapy, hormone therapy, or mTOR inhibitors [64-66]. Here, FASNipromoted upregulation of pro-apoptotic $\mathrm{BH} 3$-only proteins was rescued by the FASN end-product palmitate, revealing that starvation of endogenously produced FAs should be added to the list of metabolic stresses capable of eliciting mitochondrial priming and augmented responsiveness to $\mathrm{BH} 3$ mimetics [67-71]. Regardless of the interconnected hierarchical model explaining how the BCL-2 family proteins dictate cellular survival versus mitochondriondependent cell death [72-76], we now provide solid evidence that intrinsic/primary unresponsiveness of cancer cells to BCL2-targeting
BH3 mimetics can be circumvented by promoting a high mitochondrial primed-for-death state with FASNis.

The in vivo efficacy data in a xenograft cancer model validating the actionable synergistic interaction between a clinical grade-like FASNi and the BH3 mimetics ABT-263/navitoclax and venetoclax/ ABT-199 strongly support the exploration of their combination in the clinic. Transcriptomic and proteomic data have confirmed that $\mathrm{HER2}^{+}$breast tumors are the highest FASN-expressors among breast cancer subtypes [77-81]. The HER2-FASN lipogenic axis therefore delineates a subgroup of patients that might benefit from therapeutic regimens containing $\mathrm{FASNis}$ and $\mathrm{BCL}-2 \mathrm{BH} 3$ mimetics. The recent discovery that brain metastases in $\mathrm{HER2}^{+}$ breast cancer patients rely on FASN $[82,83]$ illuminates the important translational impact of combining blood-brain-barrier penetrable versions of FASNis and $\mathrm{BCL}-2$ BH3 mimetics such as venetoclax, which has already shown a potential efficacy in the treatment of malignancies with central nervous system involvement [84-86].

\section{CONCLUSIONS}

We here add FASN-dependent endogenous lipogenesis to the list of metabolic pathways closely intertwined with apoptotic cell death in cancer cells. We propose that heightened mitochondrial priming is the basis for the apoptotic hypersensitivity of cancer cells starved of FASN-synthesized de novo FAs. Thus, the capacity of FASN activity to regulate mitochondrial priming correlates with, and may be a determinant of the therapeutic index of FASNis. Our findings support a mitochondrial basis to explore the actionable synergistic interaction between FASNis and $\mathrm{BH} 3-$ mimetics targeting $\mathrm{BCL}-2$ in the clinic setting.

\section{DATA AVAILABILITY}

The data that support the findings of this study are available from the corresponding authors, upon reasonable request.

\section{REFERENCES}

1. Ward PS, Thompson CB. Metabolic reprogramming: a cancer hallmark even warburg did not anticipate. Cancer Cell. 2012;21:297-308.

2. Pavlova NN, Thompson CB. The emerging hallmarks of cancer metabolism. Cell Metab. 2016;23:27-47.

3. DeBerardinis RJ, Chandel NS. Fundamentals of cancer metabolism. Sci Adv. 2016;2:e1600200.

4. Faubert B, Solmonson A, DeBerardinis RJ. Metabolic reprogramming and cancer progression. Science 2020;368:eaaw5473.

5. Röhrig F, Schulze A. The multifaceted roles of fatty acid synthesis in cancer. Nat Rev Cancer. 2016;16:732-49.

6. Koundouros N, Poulogiannis G. Reprogramming of fatty acid metabolism in cancer. Br J Cancer. 2020;122:4-22.

7. Baenke F, Peck B, Miess H, Schulze A. Hooked on fat: the role of lipid synthesis in cancer metabolism and tumour development. Dis Model Mech. 2013;6:1353-63.

8. Menendez JA, Lupu R. Fatty acid synthase and the lipogenic phenotype in cancer pathogenesis. Nat Rev Cancer. 2007;7:763-77.

9. Jones SF, Infante JR. Molecular pathways: fatty acid synthase. Clin Cancer Res. 2015;21:5434-8.

10. Bueno MJ, Quintela-Fandino M. Emerging role of fatty acid synthase in tumor initiation: implications for cancer prevention. Mol Cell Oncol. 2020;7:1709389.

11. Montesdeoca N, López M, Ariza X, Herrero L, Makowski K. Inhibitors of lipogenic enzymes as a potential therapy against cancer. FASEB J. 2020;34:11355-81.

12. Menendez JA, Lupu R. Fatty acid synthase (FASN) as a therapeutic target in breast cancer. Expert Opin Ther Targets. 2017;21:1001-16.

13. Stoiber K, Nagło O, Pernpeintner C, Zhang S, Koeberle A, Ulrich M, et al. Targeting de novo lipogenesis as a novel approach in anti-cancer therapy. $\mathrm{Br} \mathrm{J}$ Cancer. 2018;118:43-51.

14. Fhu CW, Ali A. Fatty acid synthase: an emerging target in cancer. Molecules 2020;25:E3935.

15. Slebe F, Rojo F, Vinaixa M, García-Rocha M, Testoni G, Guiu M, et al. FoxA and LIPG endothelial lipase control the uptake of extracellular lipids for breast cancer growth. Nat Commun. 2016;7:1119915. 
16. Bueno MJ, Jimenez-Renard V, Samino S, Capellades J, Junza A, López-Rodríguez $\mathrm{ML}$, et al. Essentiality of fatty acid synthase in the $2 \mathrm{D}$ to anchorage-independent growth transition in transforming cells. Nat Commun. 2019;10:5011.

17. Guadamillas MC, Cerezo A, Del Pozo MA. Overcoming anoikis-pathways to anchorage-independent growth in cancer. J Cell Sci. 2011;124:3189-97.

18. Paoli P, Giannoni E, Chiarugi P. Anoikis molecular pathways and its role in cancer progression. Biochim Biophys Acta. 2013;1833:3481-98.

19. Mason JA, Hagel KR, Hawk MA, Schafer ZT. Metabolism during ECM Detachment: Achilles heel of cancer cells? Trends Cancer. 2017;3:475-81.

20. Hawk MA, Schafer ZT. Mechanisms of redox metabolism and cancer cell survival during extracellular matrix detachment. J Biol Chem. 2018;293:7531-7.

21. Bandyopadhyay S, Zhan R, Wang Y, Pai SK, Hirota S, Hosobe S, et al. Mechanism of apoptosis induced by the inhibition of fatty acid synthase in breast cancer cells. Cancer Res. 2006;66:5934-40.

22. Zecchin KG, Rossato FA, Raposo HF, Melo DR, Alberici LC, Oliveira HC, et al. Inhibition of fatty acid synthase in melanoma cells activates the intrinsic pathway of apoptosis. Lab Invest. 2011;91:232-40.

23. Heiligtag SJ, Bredehorst R, David KA. Key role of mitochondria in ceruleninmediated apoptosis. Cell Death Differ. 2002;9:1017-25.

24. Cui $Y$, Xing P, Wang Y, Liu M, Qiu L, Ying G, et al. NADPH accumulation is responsible for apoptosis in breast cancer cells induced by fatty acid synthase inhibition. Oncotarget 2017;8:32576-85.

25. Rossato FA, Zecchin KG, La Guardia PG, Ortega RM, Alberici LC, Costa RA, et al Fatty acid synthase inhibitors induce apoptosis in non-tumorigenic melan-a cells associated with inhibition of mitochondrial respiration. PLoS ONE. 2014;9: e101060.

26. Ryan J, Montero J, Rocco J, Letai A. iBH3: simple, fixable BH3 profiling to determine apoptotic priming in primary tissue by flow cytometry. Biol Chem. 2016;397:671-8

27. Alcon C, Manzano-Muñoz A, Prada E, Mora J, Soriano A, Guillén G, et al. Sequential combinations of chemotherapeutic agents with $\mathrm{BH} 3$ mimetics to treat rhabdomyosarcoma and avoid resistance. Cell Death Dis. 2020;11:634

28. Alcon C, Gómez Tejeda Zañudo J, Albert R, Wagle N, Scaltriti M, Letai A, et al. ER+ breast cancer strongly depends on $\mathrm{MCL}-1$ and $\mathrm{BCL}-\mathrm{xL}$ anti-apoptotic proteins. Cells 2021:10:1659.

29. Garrido C, Galluzzi L, Brunet M, Puig PE, Didelot C, Kroemer G. Mechanisms of cytochrome c release from mitochondria. Cell Death Differ. 2006;13:1423-33.

30. Knudson CM, Brown NM. Mitochondria potential, bax "activation," and programmed cell death. Methods Mol Biol. 2008;414:95-108.

31. Lim ML, Lum MG, Hansen TM, Roucou X, Nagley P. On the release of cytochrome $c$ from mitochondria during cell death signaling. J Biomed Sci. 2002;9:488-506.

32. Ly JD, Grubb DR, Lawen A. The mitochondrial membrane potential (deltapsi(m)) in apoptosis; an update. Apoptosis 2003;8:115-28.

33. Zafarullah M, Li WQ, Sylvester J, Ahmad M. Molecular mechanisms of $\mathrm{N}$-acetylcysteine actions. Cell Mol Life Sci. 2003;60:6-20.

34. Shimamoto $K$, Hayashi $H$, Taniai E, Morita R, Imaoka M, Ishii $Y$, et al. Antioxidant Nacetyl-L-cysteine (NAC) supplementation reduces reactive oxygen species (ROS)mediated hepatocellular tumor promotion of indole-3-carbinol (I3C) in rats. J Toxicol Sci. 2011;36:775-86.

35. Son Y, Kim S, Chung HT, Pae HO. Reactive oxygen species in the activation of MAP kinases. Methods Enzymol. 2013;528:27-48.

36. Ueda $\mathrm{S}$, Masutani $\mathrm{H}$, Nakamura $\mathrm{H}$, Tanaka $T$, Ueno $M$, Yodoi J. Redox control of cell death. Antioxid Redox Signal. 2002;4:405-14.

37. Cardaci S, Filomeni G, Ciriolo MR. Redox implications of AMPK-mediated signal transduction beyond energetic clues. J Cell Sci. 2012;125:2115-25.

38. Certo M, Del Gaizo Moore V, Nishino M, Wei G, Korsmeyer S, Armstrong SA, et al Mitochondria primed by death signals determine cellular addiction to antiapoptotic BCL-2 family members. Cancer Cell. 2006;9:351-65.

39. Deng J, Carlson N, Takeyama K, Dal Cin P, Shipp M, Letai A. BH3 profiling identifies three distinct classes of apoptotic blocks to predict response to ABT-737 and conventional chemotherapeutic agents. Cancer Cell. 2007;12:171-85.

40. Del Gaizo Moore V, Letai A. Rational design of therapeutics targeting the BCL-2 family: are some cancer cells primed for death but waiting for a final push? Adv Exp Med Biol. 2008;615:159-75.

41. Ryan JA, Brunelle JK, Letai A. Heightened mitochondrial priming is the basis for apoptotic hypersensitivity of CD4+ CD8+ thymocytes. Proc Natl Acad Sci USA. 2010;107:12895-900.

42. Ni Chonghaile T, Sarosiek KA, Vo TT, Ryan JA, Tammareddi A, Moore Vdel G, et al. Pretreatment mitochondrial priming correlates with clinical response to cytotoxic chemotherapy. Science 2011;334:1129-33.

43. Vo $\Pi$, Ryan J, Carrasco R, Neuberg D, Rossi DJ, Stone RM, et al. Relative mitochondrial priming of myeloblasts and normal HSCs determines chemotherapeutic success in AML. Cell 2012;151:344-55.
44. Del Gaizo Moore V, Letai A. BH3 profiling-measuring integrated function of the mitochondrial apoptotic pathway to predict cell fate decisions. Cancer Lett. 2013;332:202-5

45. Montero J, Sarosiek KA, DeAngelo JD, Maertens O, Ryan J, Ercan D, et al. Druginduced death signaling strategy rapidly predicts cancer response to chemotherapy. Cell 2015;160:977-89.

46. Butterworth M, Pettitt A, Varadarajan S, Cohen GM. BH3 profiling and a toolkit of $\mathrm{BH} 3$-mimetic drugs predict anti-apoptotic dependence of cancer cells. $\mathrm{Br} \mathrm{J}$ Cancer. 2016;114:638-41.

47. Kuehl T, Lagares D. BH3 mimetics as anti-fibrotic therapy: unleashing the mitochondrial pathway of apoptosis in myofibroblasts. Matrix Biol. 2018;68-69:94-105

48. Aregger M, Lawson KA, Billmann M, Costanzo M, Tong AHY, Chan K, et al. Systematic mapping of genetic interactions for de novo fatty acid synthesis identifies C12orf49 as a regulator of lipid metabolism. Nat Metab. 2020;2:499-513.

49. Tse C, Shoemaker AR, Adickes J, Anderson MG, Chen J, Jin S, et al. ABT-263: a potent and orally bioavailable Bcl-2 family inhibitor. Cancer Res. 2008;68:3421-8.

50. Chen J, Jin S, Abraham V, Huang X, Liu B, Mitten MJ, et al. The Bcl-2/Bcl-X(L)/Bcl-w inhibitor, navitoclax, enhances the activity of chemotherapeutic agents in vitro and in vivo. Mol Cancer Ther. 2011;10:2340-9.

51. Thompson BJ, Stern A, Smith S. Purification and properties of fatty acid synthetase from a human breast cell line. Biochim Biophys Acta. 1981;662:125-30.

52. Kuhajda FP, Jenner K, Wood FD, Hennigar RA, Jacobs LB, Dick JD, et al. Fatty acid synthesis: a potential selective target for antineoplastic therapy. Proc Natl Acad Sci USA. 1994:91:6379-83.

53. Green DR. A BH3 mimetic for killing cancer cells. Cell 2016;165:1560.

54. Roberts AW, Huang D. Targeting BCL2 with BH3 mimetics: basic science and clinical application of venetoclax in chronic lymphocytic leukemia and related $B$ cell malignancies. Clin Pharm Ther. 2017;101:89-98.

55. Merino D, Kelly GL, Lessene G, Wei AH, Roberts AW, Strasser A. BH3-mimetic drugs: blazing the trail for new cancer medicines. Cancer Cell. 2018;34:879-91.

56. Falchook G, Infante J, Arkenau HT, Patel MR, Dean E, Borazanci E, et al. First-inhuman study of the safety, pharmacokinetics, and pharmacodynamics of first-inclass fatty acid synthase inhibitor TVB-2640 alone and with a taxane in advanced tumors. EClinicalMedicine. 2021;34:100797.

57. Loomba R, Mohseni R, Lucas KJ, Gutierrez JA, Perry RG, Trotter JF, et al. TVB-2640 (FASN inhibitor) for the treatment of nonalcoholic steatohepatitis: FASCINATE-1, a randomized, placebo-controlled Ph2a trial. Gastroenterology 2021;S00165085:03276-5.

58. Ventura R, Mordec K, Waszczuk J, Wang Z, Lai J, Fridlib M, et al. Inhibition of de novo palmitate synthesis by fatty acid synthase induces apoptosis in tumor cells by remodeling cell membranes, inhibiting signaling pathways, and reprogramming gene expression. EBioMedicine 2015;2:808-24.

59. Heuer TS, Ventura R, Mordec K, Lai J, Fridlib M, Buckley D, et al. FASN inhibition and taxane treatment combine to enhance anti-tumor efficacy in diverse xenograft tumor models through disruption of tubulin palmitoylation and microtubule organization and FASN inhibition-mediated effects on oncogenic signaling and gene expression. EBioMedicine 2017;16:51-62.

60. Buckley D, Duke G, Heuer TS, O'Farrell M, Wagman AS, McCulloch W, et al. Fatty acid synthase-modern tumor cell biology insights into a classical oncology target. Pharm Ther. 2017;177:23-31.

61. Zaytseva YY, Rychahou PG, Le AT, Scott TL, Flight RM, Kim JT, et al. Preclinical evaluation of novel fatty acid synthase inhibitors in primary colorectal cancer cells and a patient-derived xenograft model of colorectal cancer. Oncotarget 2018;9:24787-800.

62. Montero J, Letai $A$. Why do BCL-2 inhibitors work and where should we use them in the clinic? Cell Death Differ. 2018;25:56-64.

63. Scarfò L, Ghia P. Reprogramming cell death: BCL2 family inhibition in hematological malignancies. Immunol Lett. 2013;155:36-9.

64. Stamelos VA, Redman CW, Richardson A. Understanding sensitivity to $\mathrm{BH} 3$ mimetics: ABT-737 as a case study to foresee the complexities of personalized medicine. J Mol Signal. 2012;7:12.

65. Oakes SR, Vaillant F, Lim E, Lee L, Breslin K, Feleppa F, et al. Sensitization of BCL-2expressing breast tumors to chemotherapy by the $\mathrm{BH} 3$ mimetic ABT-737. Proc Natl Acad Sci USA. 2012;109:2766-71.

66. Vaillant F, Merino D, Lee L, Breslin K, Pal B, Ritchie ME, et al. Targeting BCL-2 with the $\mathrm{BH} 3$ mimetic ABT-199 in estrogen receptor-positive breast cancer. Cancer Cell. 2013;24:120-9.

67. Braun F, Bertin-Ciftci J, Gallouet AS, Millour J, Juin P. Serum-nutrient starvation induces cell death mediated by Bax and Puma that is counteracted by p21 and unmasked by Bcl-x(L) inhibition. PLoS ONE. 2011;6:e23577.

68. Ramírez-Peinado S, Alcázar-Limones F, Lagares-Tena L, El Mjiyad N, CaroMaldonado A, Tirado $\mathrm{OM}$, et al. 2-deoxyglucose induces Noxa-dependent apoptosis in alveolar rhabdomyosarcoma. Cancer Res 2011;71:6796-806.

69. Zagorodna O, Martin SM, Rutkowski DT, Kuwana T, Spitz DR, Knudson CM. 2 deoxylgucose-induced toxicity is regulated by $\mathrm{Bcl}-2$ family members and is 
enhanced by antagonizing $\mathrm{Bcl}-2$ in lymphoma cell lines. Oncogene. 2012;31:2738-49.

70. Zhao Y, Coloff JL, Ferguson EC, Jacobs SR, Cui K, Rathmell JC. Glucose metabolism attenuates p53 and Puma-dependent cell death upon growth factor deprivation. J Biol Chem. 2008;283:36344-53.

71. Al-Zebeeby A, Vogler M, Milani M, Richards C, Alotibi A, Greaves G, et al. Targeting intermediary metabolism enhances the efficacy of $\mathrm{BH} 3$ mimetic therapy in hematologic malignancies. Haematologica. 2019;104:1016-25.

72. Pang YP, Dai H, Smith A, Meng XW, Schneider PA, Kaufmann SH. Bak conformational changes induced by ligand binding: insight into $\mathrm{BH} 3$ domain binding and Bak homo-oligomerization. Sci Rep. 2012;2:257.

73. Chen $\mathrm{HC}$, Kanai $M$, Inoue-Yamauchi $A$, Tu HC, Huang $Y$, Ren $D$, et al. An interconnected hierarchical model of cell death regulation by the BCL-2 family. Nat Cell Biol. 2015;17:1270-81.

74. O'Neill KL, Huang K, Zhang J, Chen Y, Luo X. Inactivation of prosurvival Bcl-2 proteins activates Bax/Bak through the outer mitochondrial membrane. Genes Dev. 2016;30:973-88.

75. Greaves G, Milani M, Butterworth M, Carter RJ, Byrne DP, Eyers PA, et al. BH3-only proteins are dispensable for apoptosis induced by pharmacological inhibition of both MCL-1 and BCL-X. Cell Death Differ. 2019;26:1037-47.

76. Adams JM. BAX and BAK become killers without a BH3 trigger. Cell Res. 2019;29:967-8.

77. Menendez JA, Peirce SK, Papadimitropoulou A, Cuyàs E, Steen TV, Verdura S, et al. Progesterone receptor isoform-dependent cross-talk between prolactin and fatty acid synthase in breast cancer. Aging. 2020;12:24671-92.

78. Menendez JA, Papadimitropoulou A, Vander Steen T, Cuyàs E, Oza-Gajera BP, Verdura $S$, et al. Fatty acid synthase confers tamoxifen resistance to ER+/HER2+ breast cancer. Cancers. 2021;13:1132.

79. Menendez JA, Vellon L, Mehmi I, Oza BP, Ropero S, Colomer R, et al. Inhibition of fatty acid synthase (FAS) suppresses HER2/neu (erbB-2) oncogene overexpression in cancer cells. Proc Natl Acad Sci USA. 2004;101:10715-20.

80. Menendez JA, Mehmi I, Verma VA, Teng PK, Lupu R. Pharmacological inhibition of fatty acid synthase (FAS): a novel therapeutic approach for breast cancer chemoprevention through its ability to suppress Her-2/neu (erbB-2) oncogeneinduced malignant transformation. Mol Carcinog. 2004;41:164-78.

81. Corominas-Faja B, Vellon L, Cuyàs E, Buxó M, Martin-Castillo B, Serra D, et al. Clinical and therapeutic relevance of the metabolic oncogene fatty acid synthase in HER2+ breast cancer. Histol Histopathol. 2017;32:687-98.

82. Jin X, Demere Z, Nair K, Ali A, Ferraro GB, Natoli T, et al. A metastasis map of human cancer cell lines. Nature 2020;588:331-6.

83. Ferraro GB, Ali A, Luengo A, Kodack DP, Deik A, Abbott KL, et al. Fatty acid synthesis is required for breast cancer brain metastasis. Nat Cancer. 2021;2:414-28.

84. Reda G, Cassin R, Dovrtelova G, Matteo C, Giannotta J, D'Incalci M, et al. Venetoclax penetrates in cerebrospinal fluid and may be effective in chronic lymphocytic leukemia with central nervous system involvement. Haematologica. 2019;104:e222-e223.

85. Beziat G, Gauthier M, Protin C, Oberic L, Lerebours F, Carlier J, et al. Venetoclax with high-dose methotrexate and rituximab seem effective and well-tolerated in the treatment of central nervous system involvement of chronic lymphocytic leukemia: a case report. Clin Case Rep. 2020;8:269-73.

86. Zhang $X$, Chen J, Wang W, Li X, Tan Y, Zhang X, et al. Treatment of central nervous system relapse in acute promyelocytic leukemia by venetoclax: a case report. Front Oncol. 2021;11:693670.

\section{ACKNOWLEDGEMENTS}

The authors would like to thank Dr. Kenneth McCreath for editorial support. This work was supported by the NIH National Cancer Institute Grants R01 CA116623 (to Ruth Lupu) and R01 CA166741 (to Scott H. Kaufmann) and by the U.S. Department of Defense (DOD)-Breakthrough 3 Grants BC151072 and BC151072P1 (to Ruth Lupu). Work in the Menendez laboratory is supported by the Spanish Ministry of Science and Innovation (Grants SAF2016-80639-P and PID2019-10455GB-100, Plan Nacional de I $+D+$ I, founded by the European Regional Development Fund, Spain) and by an unrestricted research grant from the Fundació Oncolliga Girona (Lliga catalana d'ajuda al malalt de càncer, Girona). Joan Montero acknowledges support from the Ramon y Cajal Programme, Ministerio de Economía y Competitividad (RYC-201518357) and the Spanish National Plan "Retos Investigación" I+D + I (RTI2018094533-A-100) from the Ministerio de Ciencia, Innovación y Universidades. Elisabet Cuyàs holds a research contract "Miguel Servet" (CP20/00003) from the Instituto de
Salud Carlos III, Spanish Ministry of Science and Innovation (Spain). All authors have read and agreed to the published version of the manuscript.

\section{AUTHOR CONTRIBUTIONS}

Barbara Schroeder: Investigation, validation, formal analysis, data curation. Ingrid Espinoza: Investigation, validation, formal analysis, data curation. Travis Vander Steen: Investigation, formal analysis, data curation. Chandra M. Kurapaty Venkatapoorna: Investigation, formal analysis, data curation. Zeng Hu: Investigation, formal analysis, data curation. Fernando Martín Silva: Investigation, formal analysis, data curation. Kevin Regan: Investigation, formal analysis, data curation. Elisabet Cuyàs: Investigation, formal analysis, data curation. X. Wei Meng: Investigation, formal analysis, data curation. Sara Verdura: Investigation, formal analysis, data curation. Aina Arbusà: Investigation, formal analysis, data curation. Paula A. Schneider: Investigation, formal analysis, data curation. Karen S. Flatten: Investigation, formal analysis, data curation. George Kemble: Conceptualization, resources. Joan Montero: Methodology, validation, resources; supervision. Scott H. Kaufmann: Conceptualization, validation, resources, supervision, funding acquisition, writing-review \& editing. Javier A. Menendez: Conceptualization, methodology, validation, formal analysis, resources, writing_original draft, writing-review \& editing, supervision, funding acquisition. Ruth Lupu: Conceptualization, methodology, validation, formal analysis, resources, writing-original draft, writing-review \& editing, supervision, funding acquisition. All authors have read and agreed to the submitted version of the manuscript.

\section{COMPETING INTERESTS}

George Kemble is the Chief Executive Officer and Chief Scientific Officer at Sagimet Biosciences (formerly known as 3-V Biosciences). Joan Montero reports previous consulting for Vivid Biosciences and Oncoheroes Biosciences, current collaboration with AstraZeneca, and an unpaid board membership for The Society for Functional Precision Medicine. All the other authors declare that the research was conducted in the absence of any commercial or financial relationships that could be construed as a potential conflict of interest.

\section{ETHICS APPROVAL}

Animal studies were conducted in accordance with the Guide for the Care and Use of Laboratory Animals and approved by the Mayo Institutional Animal Care and Use Committee (IACUC).

\section{ADDITIONAL INFORMATION}

Supplementary information The online version contains supplementary material available at https://doi.org/10.1038/s41419-021-04262-x.

Correspondence and requests for materials should be addressed to Javier A. Menendez or Ruth Lupu.

Reprints and permission information is available at http://www.nature.com/ reprints

Publisher's note Springer Nature remains neutral with regard to jurisdictional claims in published maps and institutional affiliations. adaptation, distribution and reproducton in any medium or format, as long as you give appropriate credit to the original author(s) and the source, provide a link to the Creative Commons license, and indicate if changes were made. The images or other third party material in this article are included in the article's Creative Commons license, unless indicated otherwise in a credit line to the material. If material is not included in the article's Creative Commons license and your intended use is not permitted by statutory regulation or exceeds the permitted use, you will need to obtain permission directly from the copyright holder. To view a copy of this license, visit http://creativecommons. org/licenses/by/4.0/.

(c) The Author(s) 2021 